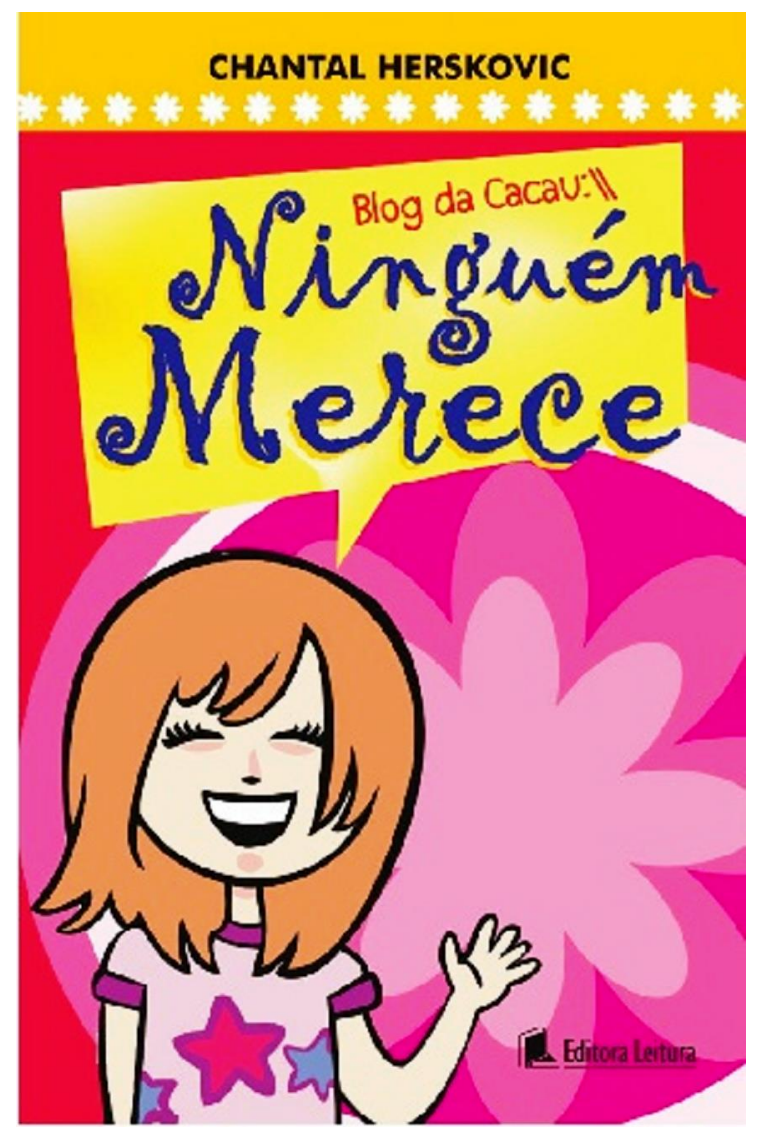

Capa do livro

\title{
Bate-papo com Chantal: / / A gente merece
}

Chantal Herskovic

por Ângela Carneiro Ricardo e Leila Cristina Barros

Colaboração de Anderson Higino
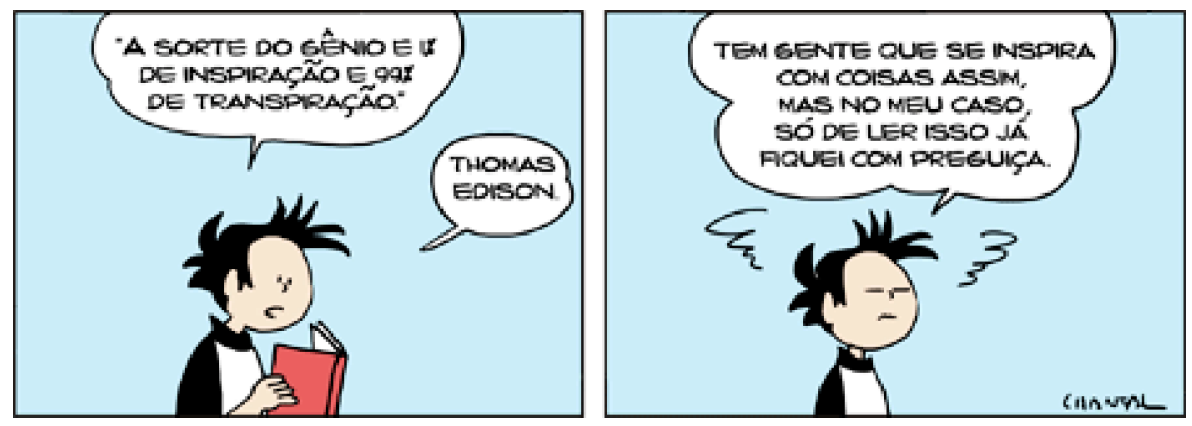

Chantal Herskovic é quadrinista e, diariamente, publica tiras no jornal Estado de Minas. É mestre em Artes Visuais pela 
Escola de Belas Artes da Universidade Federal de Minas Gerais (UFMG), na área de cinema de animação, e especialista em Comunicação (novas tecnologias e hipermídia) pelo centro Universitário de Belo Horizonte (UNI-BH). Também possui formação em Design Gráfico pela Escola de Design da Universidade do Estado de Minas Gerais (UEMG), é integrante do grupo de pesquisa INTERMIDIA, da Faculdade de Letras da UFMG, e professora do curso de Comunicação das Faculdades Promove.

Ângela Carneiro Ricardo é psicóloga, psicanalista, esquizoanalista e analista institucional. É coordenadora geral do Núcleo de Psicanálise e Práticas Institucionais e integrante do Programa de Ensino, Pesquisa e Extensão A tela e o texto, da FALE/UFMG.

Leila Cristina Barros é doutoranda em Literatura Comparada (linha de pesquisa Literatura e Outros Sistemas Semióticos) na FALE/UFMG, professora de Língua Portuguesa na Rede Municipal de Ensino de Belo Horizonte e integrante do grupo de pesquisa INTERMIDIA, da FALE/UFMG.

\section{Ângela e Leila. - Fale sobre sua formação acadêmica e sua experiência de ensino de leitura/criação de imagens e textos.}

Chantal - Eu me formei em Design Gráfico na UEMG, fiz especialização em Comunicação: Novas Tecnologias e Hipermídia no Uni-BH e sou Mestre em Artes Visuais pela UFMG. Na Escola de Design, trabalhamos com imagens e textos o tempo todo. Buscamos integrar as duas mídias, de forma que se misturem e tornem-se um só objeto. Nessa abordagem, exploramos ao máximo a tipografia e elementos visuais, criamos e recriamos códigos visuais para alguma peça como um pôster ou uma marca. Até mesmo a diagramação pode ser trabalhada de forma a utilizar o corpo de texto como imagem. E o suporte também pode ser explorado, através de colagens, cortes, dobras e do uso de materiais especiais. Sempre incentivei meus alunos a explorar as diversas possibilidades gráficas para uma peça, a escrever suas idéias, a fazer obrainstorm, a discutir com os colegas para perceber pontos de vista distintos, para, assim, sair do lugar-comum e buscar a inovação. A criatividade é resultado de trabalho, pesquisa e abertura a novas idéias. 

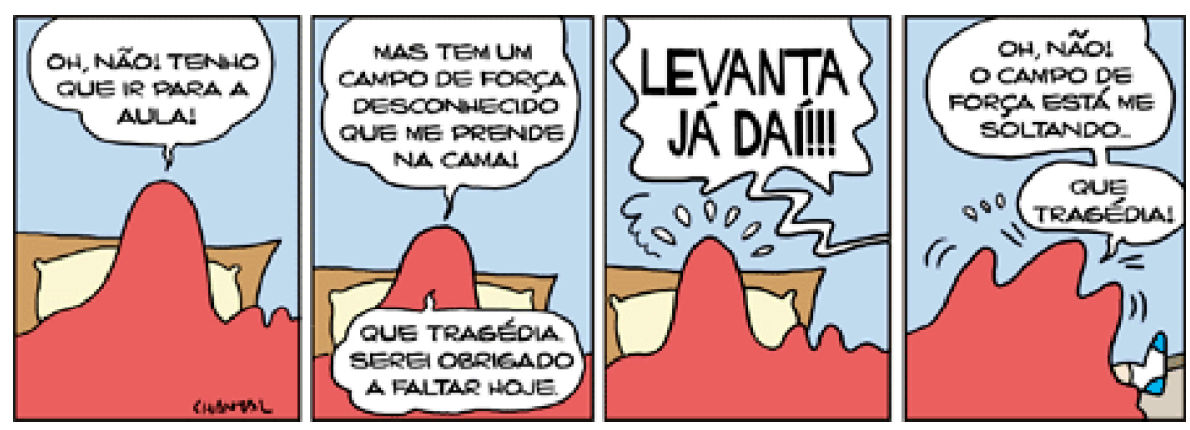

\section{Como você percebe, no ensino de leitura para jovens, o uso de novas mídias e tecnologias? Quais as possibilidades $e$ os desafios?}

Os jovens, hoje, fazem parte de uma geração habituada à comunicação digital. Eles têm acesso a celulares, internet, videogames, televisão, além das revistas, jornais, rádios e livros. Hoje, existe a linguagem visual, baseada em códigos e poucos textos, em que as informações, às vezes, não são "lidas", apenas "vistas". Há informações em excesso e pouca coisa é absorvida. A geração zapping, que fazia tudo ao mesmo tempo sem se aprofundar em nada, transformou-se na geração click, soterrada por informações, que navega em vários sites ao mesmo tempo, mantém conversas online com os amigos, entra em chats, escuta músicas e podcasts, assiste a vídeos, verifica e-mails, troca mensagens, manipula o celular, joga videogames, quase tudo ao mesmo tempo. Uma criança de três anos já tem capacidade de mexer no computador e usar jogos. Reconhece os códigos visuais e consegue mexer em um teclado, apesar de não compreendê-lo totalmente.

Apesar de esses jovens viverem em um mundo em que existem links para quase tudo, isso não quer dizer que acessem sites de museus ou pesquisas. O que procuram mais é MSN e Orkut, sendo os blogs também bastante populares. Outra coisa que ocorreu foi o surgimento de uma nova linguagem virtual, com abreviaturas e palavras com apenas uma ou duas letras. Os textos e apostilas podem ser transformados em hipertextos e existem verdadeiras enciclopédias, seja on-line ou como softwares. O aluno pode acessar informações e, eventualmente, buscar os livros citados. Para o ensino, a tecnologia é essencial. Informações cuidadosamente montadas em hipertextos e assim apresentadas aos alunos, juntamente com vídeos e imagens, podem aumentar a interação e a participação. A criação de blogs e o fato de poder publicar mesmo um trabalho, quase instantaneamente e sem custo, para que outros possam ler e comentar, tudo isso é algo que não existia há vinte anos. As listas de discussão e os fóruns também têm seu papel, se bem utilizados. São inúmeras possibilidades. O desafio é apresentar aos jovens essas opções. 

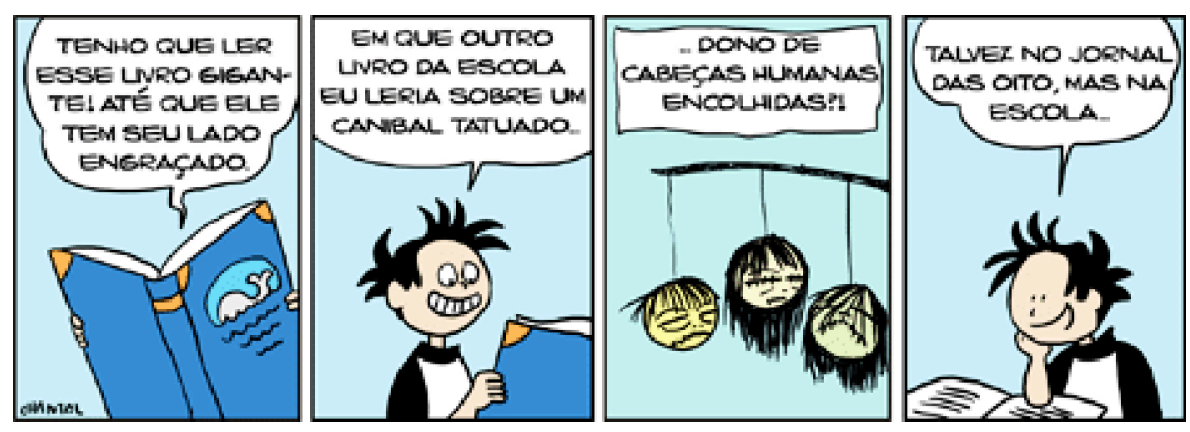

Como surgiu a idéia de estudar a série Os Simpsons em sua pesquisa de mestrado? Como foi trabalhar com um representante da cultura de massas dentro da academia?

A idéia surgiu do desejo de analisar uma animação contemporânea, seu visual e conteúdo. Escolhi Os Simpsonspor ser uma animação de sucesso internacional, com alcance global. Compreender a estrutura de sua produção e o porquê de seu sucesso foi um incentivo para a pesquisa. Na dissertação, cheguei a dedicar um capítulo especial à produção dos episódios e ao empenho dos roteiristas, que é uma das chaves do sucesso. A questão sobre a cultura de massa é que a série faz parte de um movimento de contra-cultura dentro da indústria cultural. O conteúdo subversivo, a crítica social e cultural ao american way of life, ao cotidiano, ao homem comum, ao governo, à política nacional e internacional, tudo isso explica o grande sucesso da série entre todos os tipos de pessoas, inclusive o público acadêmico. Os episódios podem ser vistos em dois níveis de leitura: um superficial e outro mais profundo. Cabe ao leitor mais atento perceber as críticas e referências intertextuais. A série, além de apontamentos sobre o que está à sua volta, também faz autocríticas, demonstrando consciência de seu papel na indústria cultural, como série de TV. Além disso, há muitas referências metalingüisticas. Por exemplo, para mostrar como é feito o desenho animadoComichão e Cocadinha, é apresentado um estúdio, na China, que explora os animadores. Há também o episódio no qual o dono do estúdio critica seus roteiristas, por não criarem um personagem atual. Aí se faz, na verdade, uma sátira às fórmulas de criação de personagens, e os produtores aparecem como donos de idéias ultrapassadas e sem sentido.
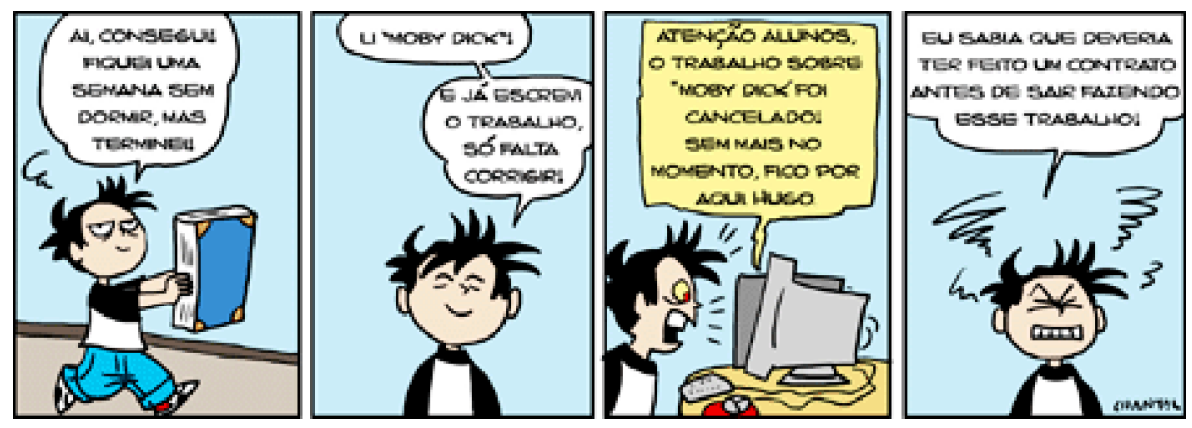


\section{Em sua pesquisa, que relações intertextuais com os cânones literários você identificou n'Os Simpsons? Que aspectos dessas releituras constituem inovações?}

Cada episódio de Os Simpsons possui muitas referências. Com o passar do tempo, as referências aumentaram, tornando-se um dos prazeres do espectador procurar reconhecer as obras citadas. E são muitas citações, que, em alguns momentos, aparecem como homenagem e, em outros, como sátira ou pastiche. As referências intertextuais feitas na série vêm da literatura, do cinema, da televisão, dos quadrinhos e das artes. A obra mais referenciada na série é o filme de Orson Welles, Cidadão kane, em que o personagem Sr. Burns seria relacionado ao próprio Kane. Além da referência ao cinema, Burns também é relacionado ao personagem Sr. Scrooge de Um Conto de Natal, de Charles Dickens. As referências não são feitas apenas nos episódios, mas também em seus títulos, tornando-se uma brincadeira como, por exemplo, em os crepes da ira, A montanha da loucura, Um conto de duas Springfields, Pigmalião, dentre outros. Há referências a Edgar Allan Poe, Melville, Mark Twain, e até mesmo a histórias bíblicas. O poema O Corvo, de Poe, foi inteiramente narrado numa história em imagens, na qual Homer sofre pela perda de Lenore, representada por Marge, e o corvo é uma caricatura de Bart. Em outras ocasiões, Bart é apresentado como Tom Sawyer e Martin Prince, seu colega de escola, até consegue fingir a própria morte, como faz Tom no livro de Mark Twain. Além disso, o filho mais velho da família Simpson também faz o papel de Hamlet e de Dr. Watson, em outros episódios. Há também referências às obras lidas (ou não) pelos personagens. Por exemplo, Bart deveria ter lido $A$ ilha do tesouro, na primeira temporada, mas nunca leu. Noutra linha de citações, entram o capitão aposentado da marinha de Springfield, que nunca capturou Moby Dick, e o episódio Das Bus, no qual as crianças vão parar na ilha de o senhor das moscas, de William Golding. Em outro episódio, a família Simpson visita a Ilha do Dr. Monroe e todos são transformados em animais, numa clara referência à obra A ilha do Dr. Moreau. Obras da literatura gótica, entre as quais Drácula e Frankenstein, são referenciadas nos episódios de Dia das Bruxas, assim como clássicos do cinema de horror. Dentre os autores contemporâneos, Tom Clancy, Stephen King, J. K. Rowling e Michael Chabon já participaram como convidados especiais. Considero essas releituras e paródias inovações, uma vez que são feitas de modo crítico em relação à contemporaneidade, à atual sociedade e à cultura de massas. Os roteiristas reinventam as obras, inserindo-as em springfield e no mundo de os Simpsons. Uma vez que os episódios são para a televisão e para o homem comum, ou seja, Homer Simpson, essas referências precisam ser feitas de forma engraçada para quem não as conhece, mas devem também preservar a possibilidade de serem interpretadas e analisadas pelo espectador crítico. 

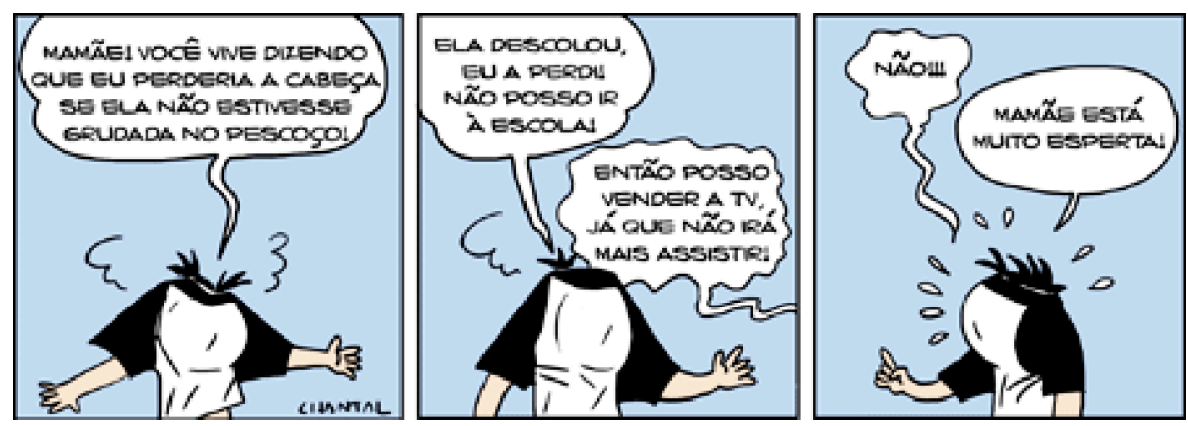

Você considera que a intertextualidade literária e fílmica, presente em vários episódios d'Os Simpsons, pode funcionar como forma de incentivo à leitura dos textos de origem?

Acredito que sim. O desenho animado é muito bem recebido pelas crianças e adolescentes, e Os Simpsons já provou seu sucesso, principalmente entre os jovens, mas também com os adultos. Assistir a um episódio, descobrir que é uma referência a uma outra obra, tudo isso desperta a curiosidade e o desejo pela leitura. O fato de a obra aparecer no desenho animado a torna mais especial para a criança, como quando a professora de Bart manda que ele leiaA ilha do tesouro ou quando ele é caracterizado como Tom Sawyer. Isso torna possível desenvolver um trabalho interessante com os alunos: apresentar-lhes a obra original e depois os episódios com as referências. Assim, os alunos podem discutir sobre adaptação e paródia, e como elas foram feitas em os Simpsons. Uma vez, em uma palestra sobre a série, em um congresso, falei das referências ao filmeCidadão Kane. Logo em seguida, descobri que os estudantes haviam acabado de assistir ao filme, para uma disciplina de cinema, e ficaram muito interessados em ver como algumas cenas haviam sido adaptadas para o desenho animado e como se deu a sátira à indústria do cinema.
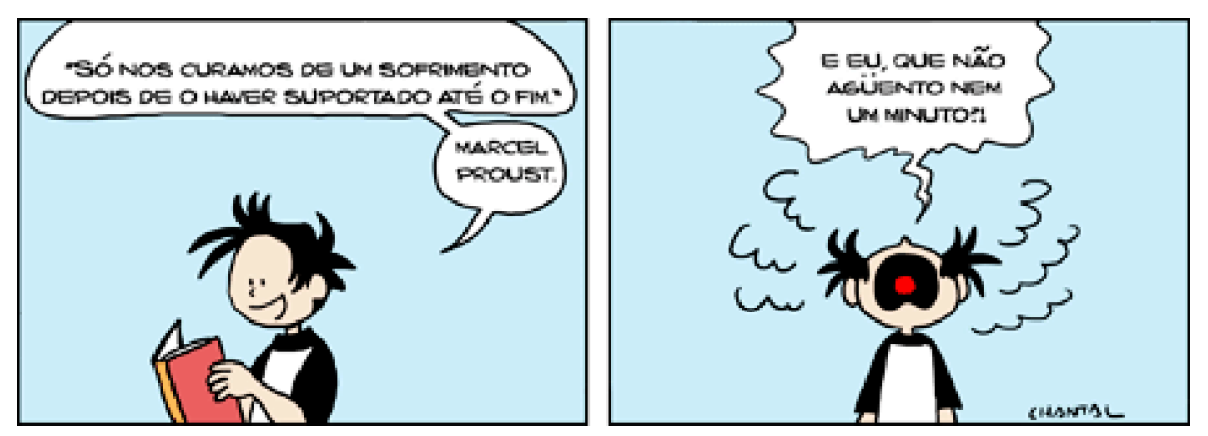

A partir do exemplo d'Os Simpsons, você diria que a TV pode tornar-se uma aliada, uma incentivadora, da leitura do texto literário? Em especial, como você vê possibilidades de conciliar a forte cultura televisiva brasileira com 0 aprofundamento dos níveis de leitura de telas e textos?

Eu acredito que ela já é uma aliada, mas ainda tem muito potencial para ser desenvolvido. Existem programas que falam 
sobre cultura, filmes e livros, além de muitos que falam sobre história e culturas antigas. Isso já mostra que existe um público interessado em aumentar seu conhecimento. Programas feitos sobre O código Da Vinci, o santo graal, J. R. R. Tolkien e Gabriel García Márquez foram apresentados com destaque na programação. Infelizmente, programas assim estão mais presentes na grade da TV por assinatura do que na TV aberta. Ainda assim, existe algum espaço e abertura, nesta última, para a divulgação de autores e suas obras, principalmente na TV regional.

o que poderia ser feito, quanto à produção brasileira, seria elevar o nível do conteúdo. Porém, a programação, em geral, é feita para o homem comum. Quando se pensa no espectador de TV, pensa-se em um Homer Simpson, que quer ver corridas de carros, programas sensacionalistas e futebol. E uma pequena parcela da audiência prefere acompanhar discussões mais sofisticadas e uma programação cultural. Na verdade, ambas as opções deveriam existir, para que o jovem espectador pudesse escolher aquilo a que realmente prefere assistir, em vez de ser levado a assistir a algo por falta de opções.

A televisão pode, sim, ajudar no incentivo à leitura. A questão é saber usá-la. Uma idéia que pode ser levada à sala de aula é propor aos alunos a leitura de um livro e, depois, fazer uma discussão em grupo e a exibição de um programa ou filme que faça paródia da obra em pauta. Por exemplo, utilizando os Simpsons, é possível falar da obra de Mark Twain e seus personagens Tom Sawyer e Huckleberry Finn, pois ambos aparecem em um episódio da série. Outra sugestão é discutir contos de fadas e, depois, mostrar o que é a paródia a partir de Shrek, que faz referências a diversos contos e filmes infantis. Alguns desses contos infantis também foram parodiados por um dos mestres da animação, Tex Avery, que recriou Chapeuzinho vermelho numa história em que o Lobo Mau é um grande paquerador, no estilo Casa Nova, e fez uma versão urbana de A cabana do Pai Tomás, na qual a casa do personagem é cercada por arranha-céus.

A criança que já possui o hábito da leitura tanto poderá buscar por si mesma a obra original quanto pedir indicações. Já a criança que não possui esse hábito será incentivada com o uso das estratégias sugeridas. É também possível utilizar a internet para incentivar pesquisas sobre os autores e sobre como suas obras teriam sido adaptadas para desenhos animados. Outra atividade com bom potencial pedagógico é a busca de ilustrações feitas por diversos artistas, a partir de obras literárias. Aliar texto e imagem é hoje um passo importante para apresentar o mundo da leitura às crianças que ainda estão aprendendo a ler e formando esse hábito. É também um recurso valioso para a interação com os jovens, que podem perceber e 
analisar diferentes níveis de interpretação de um texto, a partir de imagens produzidas por diferentes artistas, em épocas distintas, como os antigos desenhos de Alice no país das maravilhas ou uma releitura contemporânea de Cinderela.
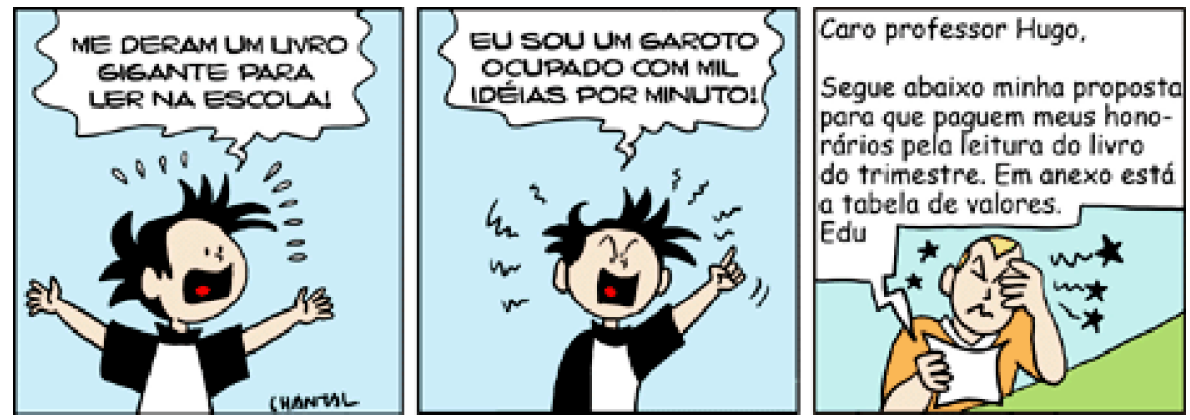

Fale um pouco sobre seu livro, que foi lançado agora em abril.

O meu livro, que acabou de ser lançado, é o Blog da Cacau: // ninguém merece. É um livro infanto-juvenil, para meninas pré-adolescentes na faixa dos oito aos doze anos ou mais. Cacau, a personagem, é uma menina de onze anos, cheia de idéias, que resolve fazer um blog e compartilhar seus dramas da quase-adolescência, suas dúvidas e histórias. O irmão, de quinze anos, vai para um intercâmbio, Cacau fica com seu computador, o que lhe permite navegar mais na internet e escrever o blog com calma. O livro todo é o próprio blog, porém impresso. E o design gráfico foi desenvolvido de forma a criar essa ligação com os blogs que existem na rede. No final do livro, apresento um minidicionário de internetês e outro de desenhos utilizando o teclado como para fazer rostinhos felizes $\odot$ ou tristes $\odot$.

No livro, escrevi sobre problemas da idade, paqueras virtuais, mundinhos virtuais, desenho animado, internet e assuntos assim. Ao final de cada capítulo, Cacau dá alguma dica à turma, para ajudar a sobreviver à adolescência. Foi ótimo o processo de escrever o livro e também de ilustrar e trabalhar seu design. Foi um grande prazer e espero que todos gostem do resultado. (:)

Entrevista feita por e-mail, entre fevereiro e abril de 2008 . 